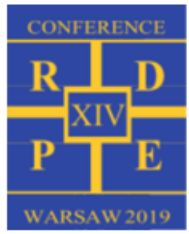

\title{
Heat transfer characteristics of an external tube heat exchanger in a 1296t/h circulating fluidized bed boiler
}

\author{
Artur Blaszczuk ${ }^{1, *}$ and Szymon Jagodzik ${ }^{2}$ \\ ${ }^{1}$ Czestochowa U niversity of Technology, Institute of A dvances Energy Technologies, Dabrowskiego 71, 42-200 Czestochowa, \\ ablaszczuk@is.pcz.pl, Poland \\ 2 Tauron Wytwarzanie S.A., Lagisza Power Plant, Pokoju 14, 42-500 B edzin, Poland
}

\begin{abstract}
In this research article, experimental study was carried out to obtain the heat transfer characteristics between a submerged horizontal tube bundle and a fluidized bed in a large-scale circulating fluidized bed (CFB) boiler with an external heat exchanger (EHE). The operational parameters in the tube EHE were measured during performance tests at variable load conditions. The average heat transfer coefficient (HTC) was calculated using a mechanistic heat transfer model based on packed renewal theory. The heat transfer characteristics are considered in terms of heat transfer mechanisms such as emulsion phase convection, gas convection and al so thermal radiation. The obtained heat transfer data exhibit a maximum value with variation mean bed particle size irrespective of pressure. The results showed that the average HTC increases with a decrease of the Sauter mean particle diameter and with the increase of the fluidizing number as a result of good mixing dynamics in emulsion phase (i.e. emulsion wall contact time, bubble fraction in the bed). Based on the heat transfer data, empirical correlations are proposed for predicting a heat transfer coefficient from fluidized bed to horizontal tube bundle. The mechanistic heat transfer model predicted the average HTC in sufficiently good agreement with CFB boiler data accessible in the literature.
\end{abstract}

\section{Introduction}

Knowledge about the heat transfer coefficient from bubbling fluidized bed particles to the tube heat exchanger is necessary for an optimal/more reliable design and scaling-up of heat transfer surfaces in processes where the control of temperature plays an essential role from the point of view of proper operation and optimum performance of CFB boilers. This is especially important in the case of CFB combustors fired with various fuel types, at turn down boiler loads and also $\mathrm{SO}_{2}$ and $\mathrm{NO}_{x}$ emission control levels.

The heat transfer between the tubular surface and bed particles depends on the local properties of the emulsion phase (i.e. heat conductivity, emulsion density, emulsion heat capacity) and also the properties of the bubbling bed (i.e. bubble fraction and emulsion-wall contact time with horizontal tube bundles). The above mentioned properties affect the dynamics of the emulsion phase mixing process, thus ensuring a uniform bed temperature, a high bed-totube heat transfer coefficient, high combustion, maintenance of proper steam temperature and flexible operation across a wide range of CFB boiler loads [1]. In addition, the flow of gas bubbles is a factor that determines the intensity of the heat transfer process from the bubbling fluidized bed to the surface of the tubular heat exchanger.

Not many researchers have studied heat flow to a horizontal tube bundle immersed in a large-scale bubbling fluidized bed so as to better understand the effect of operational parameters on the bed-to-tube heat transfer coefficient. In the last decade, several experiments have been conducted in a laboratory-scale $\mathrm{FBHE}$ with submerged horizontal tube bundles in B FB to evaluate the impact of superficial gas velocity [2] and also placement of the immersed surface [3] on the value of bed-to-tube heat transfer coefficient. Di N atale, Bareschino and Nigro [4] also studied the effect of angular position around a horizontal cylinder with the fluidization velocity on the heat transfer coefficient inside a bubbling fluidized bed. Stenberg et al. [5] investigated the influence of the particle size and the superficial velocity on the bed-to-tube surface heat transfer coefficient in a horizontal tube at a high level of bed temperature $\left(400-950^{\circ} \mathrm{C}\right)$ in a laboratory scale B FB system. In the literature, most studies focus on laboratory scale. Therefore, it is reasonable to conduct research studies focused on heat transfer characteristics of horizontal tubes submerged in large-scale gas fluidized beds.

Hence, it has been attempted in this research study to investigate the heat transfer characteristics in a large-scale bubbling fluidized bed and obtain more information about reliable predictions of the bed-to-tube heat transfer coefficient. In the present study, we have used a mechanistic heat transfer model based on the packed renewal theory $[6,7]$, which correlates the bed-to-surface heat transfer to the residence time of bed particles at the surface of horizontal tube bundles. In order to consider the impact of bubble fraction, emulsion-wall contact time, Sauter mean particle diameter, suspension density, and fluidization number on the enhancement of heat transfer in EHE, performance tests at variable CFB boiler loads were carried out. This research paper presents unique data on heat transfer between the bubbling fluidized bed and 
the horizontal tube bundles in a 1296t/h CFB boiler. It should be noted that the experimental investigations for commercial CFB systems are rarely published in the accessible scientific literature. Therefore, predicting the heat transfer characteristics will be very useful for the regulation of fluidized bed heat exchangers. B esides, the obtained heat transfer data can also be used to validate empirical correlations for the design and scale-up of heat transfer surfaces for commercial CFB boilers and bridge a gap in the accessible CFB \& BFB (bubbling fluidized bed) literature.

\section{Mechanistic heat transfer model}

The methodology to predict the bed-to-tube heat transfer coefficient was adopted from the packed renewal model proposed by Mickley and Fairbanks [7]. According to the packed renewal approach, the active heat transfer surface will be alternatively in contact with the gas bubbles and the packed particles (i.e. parcels of emulsion phase). The packed particles sweep of the active heat transfer surface in the result of the gas bubbles flow. The occurrence of gas bubbles is purely randomized.

In the mechanistic heat transfer model presented, the heat transfer process between the bubbling fluidized bed and the submerged surface for the bottom tube bundles $h_{\text {bottom }}$ in FBHE (fluidized bed heat exchanger) contains three varieties of heat transfer mechanisms, including emulsion phase convection during time of solid contact, gas convection during time of bubble contact and a radiative component in the case of high temperature operation $[8$, 9].

$$
h_{\text {bottom }}=h_{c}+h_{r}=\left(1-\delta_{b}\right) h_{e}+\delta_{b} h_{g}+h_{r},
$$

where $h_{c}$ denotes convective heat transfer coefficient, $h_{e}$ is packet particles convective heat transfer, $h_{g}$ represents gas convection heat transfer coefficient, $\delta_{b}$ denotes bubble fraction and $h_{r}$ means radiative heat transfer coefficient. A description of the individual heat transfer components in equation (1) is provided below.

The convective heat transfer coefficient due to particle packets is obtained according to the following relationship:

$$
h_{e}=\frac{2}{\pi} \sqrt{k_{e} \rho_{e} c_{e}}\left(1 / \sqrt{t_{e}}\right),
$$

where $c_{e}$ denotes emulsion phase heat capacity, $k_{e}$ represents thermal conductivity of emulsion phase, $t_{e}$ is emulsion-wall contact time and $\rho_{e}$ means density of packets (emulsion phase). Specific information on formulas on physical and thermal properties of emulsion phase is summarized in earlier work [6].

The gas convection heat transfer coefficient for the tube surface uncovered by the particle packets is estimated from the relation given by Baskakov et al. [10],

$$
h_{g}=0.009\left(k_{g} / d_{p}\right) A r^{0.5} \operatorname{Pr}^{0.33} \text {. }
$$

In the above equation (3), $A r$ denotes Archimedes number, $d_{p}$ is Sauter mean particle diameter, $k_{g}$ means thermal conductivity of gas phase and $\mathrm{Pr}$ refers to Prandtl number. The relation (3) is useable for a wide range of fluidizing conditions [11].
Thermal radiation contributes significantly to the bed-totube heat transfer coefficient especially for bubbling fluidized beds operated at high bed temperature $\left(T_{b}>\right.$ $600^{\circ} \mathrm{C}$ ). The empirical expression for the radiative heat transfer coefficient $h_{r}$ is defined as:

$$
h_{r}=\sigma\left(T_{e b}^{4}-T_{w}^{4}\right) /\left(\frac{1}{e_{b}}+\frac{1}{e_{w}}-1\right)\left(T_{e b}-T_{w}\right),
$$

where $e_{b}$ denotes effective emissivity of particles in the bed, $e_{w}$ is effective emissivity of horizontal tube surface, $T_{e b}$ means effective bed temperature, $T_{w}$ represents metal (wall) temperature and $\sigma$ refers to Stefan Boltzmann constant.

Equation (1) may not be used to predict the bed-to-tube heat transfer coefficient due to different particle packing behavior around the horizontal tube surface. There is a defluidized cap called a "lee stack" formed on the top section of tubes bundles at the velocity near the minimum fluidization velocity $U_{m f}$. For the lower portion of the tube bundles, there is an alternating character to the bubble flow around the tubes which results in a constant replacement of the emulsion phase in the bottom section. Therefore, the average heat transfer coefficient depends upon the placement of the active heat transfer surface in an external tube heat exchanger. To take into account of the influence of the tube bundle placement in the fluidized bed heat exchanger, it is necessary to calculate the bed-totube heat transfer coefficient for the top section of the tube. In this work, a semi-empirical correlation (5) based on Reynolds number $R e$, Prandtl number $P r$, tube diameter $D$, Sauter mean particle diameter $d_{p}$ and also heat capacity of packets $c_{e}$ and gas phase $c_{g}$ is used to predict the heat transfer coefficient at the top section of the tube bundles $[2,12]$.

$N u_{\text {top }}=47.56 \operatorname{Re}^{0.43} \operatorname{Pr}^{0.33}\left(D / d_{p}\right)^{-0.74}\left(c_{e} / c_{9}\right)^{-1.69} .(5)$

Thus, the final correlation regarding the average heat transfer coefficient is estimated using the following equation (6):

$$
h_{\text {avg }}=8 / 12 h_{\text {bottom }}+4 / 12 h_{\text {top }},
$$

where, $h_{\text {bottom }}$ refers to bed-to-tube heat transfer coefficient at bottom tube section and $h_{\text {top }}$ is a bed-to-tube heat transfer coefficient at top tube section. From the BFB \& CFB literature data, the relationship (6) for the average heat transfer coefficient is valid, whereas the Sauter mean particle diameter is less than $0.535 \mathrm{~mm}$.

\section{Input data to heat transfer modelling}

The packed renewal model for the heat transfer flow in the bubbling fluidized bed with submerged horizontal superheater tube bundles is based on formulas (1)-(6). Under this approach, the following assumptions are used in formulating the heat transfer flow from the fluidized bed to the horizontal bundles of smooth tubes in an external heat exchanger: (i) the packed particles temperature and the gas temperature are the same, (ii) the gas bubbles and emulsion phase are treated as a continuous flow fluidized bed, (iii) the heat transfer surface is covered by the emulsion phase or gas phase 
(bubbles), (iv) the bubble fraction in the fluidized bed is estimated in agreement with the classical two-phase theory for aggregative fluidization [12], (v) heat capacity of packets equal to the heat capacity of the solid [13]. In order to perform heat transfer modelling in accordance with the packed renewal theory, twelve performance tests were carried out under steady-state operating conditions of the CFB system. All performance tests were carried out in a $1296 \mathrm{t} / \mathrm{h}$ circulating fluidized bed boiler with an external heat exchanger $(2.7 \times 2.3 \times 1.3 \mathrm{~m}-$ depth $\times$ width $\times$ height). For all performed measurements, the test procedures are previously described by Blaszczuk and Nowak [14]. Table 1 summarizes the operating parameters used in this study. Some operating data as confidential commercial information will be not presented here.

Table 1. Test conditions in the INTREX ${ }^{\mathrm{tm}}$ heat exchanger.

\begin{tabular}{|c|c|c|}
\hline Item & Unit & Overall range \\
\hline Superficial gas velocity, $U_{\mathrm{g}}$ & $\mathrm{m} / \mathrm{s}$ & $0.14-0.26$ \\
\hline $\begin{array}{c}\text { Minimum fluidization } \\
\text { velocity, } U_{m f}\end{array}$ & $\mathrm{~m} / \mathrm{s}$ & $0.0228-0.0979$ \\
\hline Pressure drop, $\Delta p$ & $\mathrm{kPa}$ & $12.34-14.72$ \\
\hline Bed temperature, $T_{b}$ & $\mathrm{~K}$ & $929-1083$ \\
\hline Sauter particle diameter, $d_{p}$ & $\mathrm{~mm}$ & $0.219-0.444$ \\
\hline Particle density, $\rho_{p}$ & $\begin{array}{c}\mathrm{kg} / \mathrm{m} \\
3\end{array}$ & $2650-2750$ \\
\hline
\end{tabular}

The fluidized bed heat exchanger was operated with Group B particles according to Geldart@ classification (see Fig. 1).

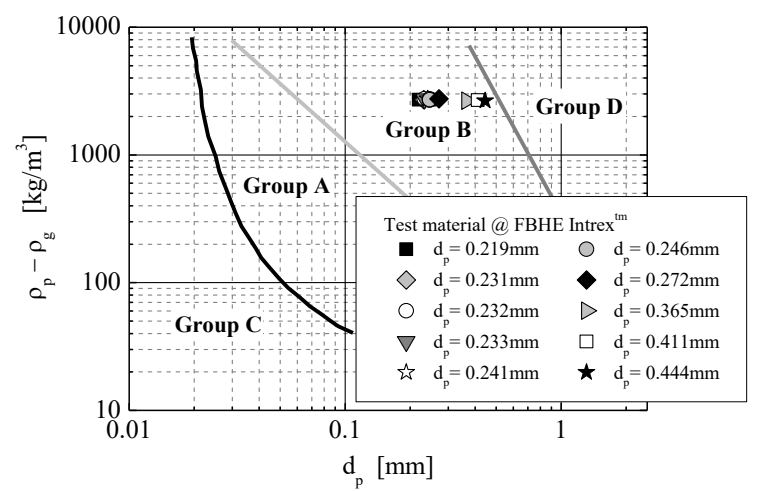

Fig. 1. Geldart powder classification of bed particles used in the FBHE at 1296t/h CFB boiler.

As can be shown in Fig. 1, the mean particle diameter of the bed material used in the FHBE is covered in a range of $0.219-0.444 \mathrm{~mm}$. Mean bed particle size is provided from a sieve analysis (i.e. direct dimensional measurement method). The device and the laboratory equipment used for the standard sieve analysis of bed material have been fully described in our other published works $[6,15]$.

In the external tube heat transfer exchanger, the horizontal tube bundles are generally arranged in staggered arrays (i.e. 32 columns $\times 12$ rows). The detailed data on the apparatus in a fluidized bed heat exchanger have been described in $[6,16]$.

\section{Results and discussions}

In this work, the predicted values of the average heat transfer coefficient for horizontal bundles of smooth tubes are obtained from the mechanistic heat transfer model based on packed renewal theory. The empirical model of heat transfer coefficient used the parameters of solids and gas in a fluidized bed heat exchanger, which were recorded at different CFB boiler loads. The findings presented in this work are given in a dimensionless scale and presented in four subsections. Some measurement data are normalized by the maximum value of the recorded parameters during all performance tests. The influence of operating parameters (mean particle size, suspension density, superficial gas velocity, bed temperature) on the heat absorption characteristics of an external tube heat exchanger in a 1296t/h circulating fluidized bed boiler are studied by means of heat transfer correlations developed by us. The computational results obtained were correlated by the authors using regression analysis. In the current heat transfer study, average heat transfer data are compared with those in the available literature.

\subsection{The correlation between average heat transfer data and Sauter mean bed particle size}

In figure 2, a calculated average bed-to-tube heat transfer coefficient is plotted against the Sauter mean particle diameter. The computational results from the packet renewal model are shown for a wide range of bed particle size (i.e. from $0.219 \mathrm{~mm}$ to $0.444 \mathrm{~mm}$ ). Each mean bed particle size was marked by an individual symbol for easier perception of findings. The average heat transfer data are heavily dependent on the mean bed particle size. During tests with the different Sauter mean diameters of bed particles, the average bed-to-tube heat transfer coefficient increased from $255-305\left[\mathrm{~W} /\left(\mathrm{m}^{2} \mathrm{~K}\right)\right]$ for coarse particle sizes (i.e. $d_{p}>0.365 \mathrm{~mm}$ ) to $317-391\left[\mathrm{~W} /\left(\mathrm{m}^{2} \mathrm{~K}\right)\right]$ in the case of fine particles (i.e. $d_{p}<0.272 \mathrm{~mm}$ ). The variation of the heat transfer coefficient is smaller for fine particles as opposed to coarser particles. The reason for such heat transfer behavior results from smaller voidage of the emulsion (packet) phase and in consequence the low emulsion packet conductivity for coarse bed particles. Fine particles have a larger number of contact points with the superheater tube wall than coarse particles. From that, therefore, it can be concluded that fine particles are more efficient in heat flow with a superheater tube surface. Wang et al. [17], Parmar et al. [18] and Pidwerbecki et al. [19] reported a similar trend in meaningful increases in the heat transfer coefficient with decreases in mean bed particle size. Heat transfer data for a bed particle size of $0.246 \mathrm{~m}$ are characterized by a high scatter of results obtained. This fact is due to different physical properties of bed particles of about the same diameter. In the packet renewal approach, the packed convective heat transfer coefficient is directly proportional to packet conductivity and inversely proportional to the square root of emulsion- 
wall contact time. So, the differences in the values of average heat transfer coefficient can come from the fluidization characteristic of these particles. A nother explanation for this fact is that the superficial gas velocity had a significant effect on the average bed-to tube heat transfer coefficient. When the bed particle size equals $0.246 \mathrm{~mm}$, the predicted values of heat transfer rate were obtained at a superficial gas velocity covering a range of $0.14-0.22 \mathrm{~m} / \mathrm{s}$.

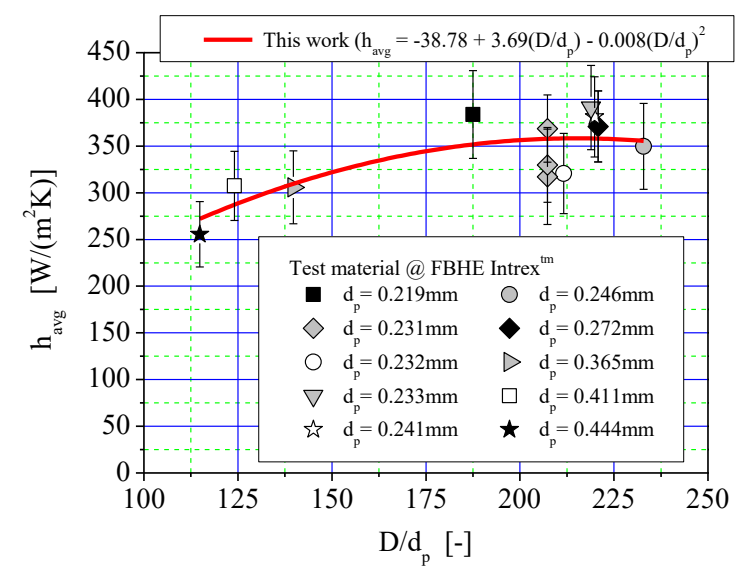

Fig. 2. Estimated average heat transfer coefficient from bed to tube at different Sauter mean particle sizes.

As can be shown in Fig. 2, at bed particle size equalling $0.233 \mathrm{~mm}$ optimal heat transfer conditions (i.e. $h_{\text {avg } \max }=$ $\left.391\left[\mathrm{~W} /\left(\mathrm{m}^{2} \mathrm{~K}\right)\right]\right)$ around the horizontal superheater tube are observed. In the present work, the heat transfer data are correlated with the ratio of diameter tube-to-mean particle size using regression analysis. The proposed empirical correlation is plotted as a red curve. The predicted values of the heat transfer coefficient have a good agreement with the proposed empirical correlation $\left(R^{2}=0.5\right.$, moderate positive correlation). The uncertainty analysis of heat transfer data is carried out on the basis of the root-sumsquare (RSS) approach. In Figs 2, 3, 4 and 5, the error bars represent uncertainty in calculated values of average heat transfer coefficient. Based on equations (1), (5) and (6), the uncertainty in the heat transfer data varied between \pm 35 and $\pm 51\left[\mathrm{~W} /\left(\mathrm{m}^{2} \mathrm{~K}\right)\right]$.

\subsection{The correlation between average heat transfer data and suspension density for horizontal superheater tube}

Fig. 3 depicts the heat transfer results of varying the suspension density for ten different mean bed particle sizes. The maximum value of the average heat transfer coefficient between the fluidized bed and the submerged superheater tube is recorded for normalized suspension density equalling 0.96 (@ $\left.\rho_{b}=1006 \mathrm{~kg} / \mathrm{m}^{3}\right)$. All bed particle sizes show an almost linear/monotonic increase in the average heat transfer coefficient with increased suspension density. This tendency of heat transfer coefficient variation versus suspension density is in accordance with other published work [6]. The predicted heat transfer data are correlated with a normalized suspension density using non-linear regression. The calculated curve represented by the red line in Fig. 3 shows the same trend with the predicted values of HTC (i.e. heat transfer coefficient). The maximum deviation of heat transfer data from the obtained correlation function does not exceed $+40\left[\mathrm{~W} /\left(\mathrm{m}^{2} \mathrm{~K}\right)\right]$ in the current study. Plot 3 presents a high positive correlation for heat transfer data values at varying levels of normalized suspension density $\left(R^{2}=0.8\right)$.

Figure 3 also reveals that the average bed-to-tube heat transfer coefficient for the fine particles appears to be somewhat higher at a high normalized suspension density (i.e. $0.91<\rho_{b} / \rho_{b \max }<1.0$ ). The exception to the above mentioned rule is the value of the average heat transfer coefficient, which has been estimated for a mean bed particle size of $0.241 \mathrm{~mm}$. This fact can be explained by a very high bubble fraction (i.e. $\delta_{b}=0.41 @ d_{p}=0.241 \mathrm{~mm}$ ) around the horizontal tube bundles immersed in a largescale bubbling fluidized bed. As a result, the bed particle had a short residence time on the tube surface (i.e. $t_{e}=$ $\left.0.13 \mathrm{~s} @ d_{p}=0.241 \mathrm{~mm}\right)$. It should be noted that the emulsion packed conductivity is several times bigger than the conductivity of the gas phase (i.e. $k_{e} / k_{g}=5$ @ $\left.d_{p}=0.241 \mathrm{~mm}\right)$. Thus, the high heat transfer rate is dependent on the interaction of the emulsion phase and gas bubbles.

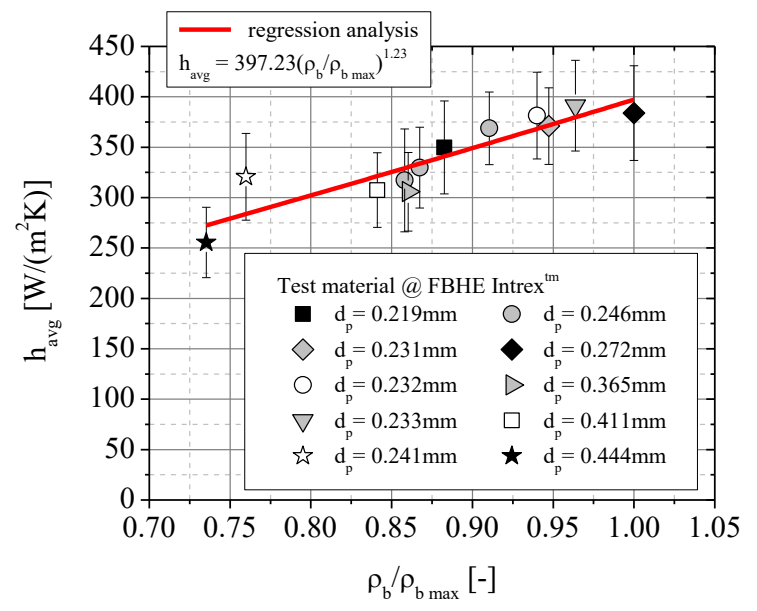

Fig. 3. Estimated average heat transfer coefficient from bed to tube at different normalized suspension densities.

Particle motion at the tube surface or particle exchange frequency (i.e. the replacement rate of packets particles by gas bubbles) depends upon excess gas velocity $\left(U_{g}-U_{m f}\right)$ or fluidization number $\left(U_{g} / U_{m f}\right)$. This issue will be discussed in the next subsection 4.3

\subsection{The correlation between average heat transfer data and fluidization number for horizontal superheater tube}

Figure 4 shows the calculated $h_{\text {avg }}$ plotted against fluidization number for bed materials with Sauter mean diameters $0.219,0.231,0.232,0233,0.241,0.246,0.272$, $0.365,0.411$ and $0.444 \mathrm{~mm}$ respectively. The results presented in Fig. 4 are computed from the model described in section 2. Heat transfer data obtained for fluidization number varied between 1.75 and 10.18. It can be seen that for a horizontal tube submerged in a fluidized bed, there is an increase of average heat transfer 
coefficient with the fluidization number. The trend variation of average heat transfer coefficient as a function of fluidization number in figure 4 has been confirmed by other researchers $[2,5,20,21]$.

The lowest heat transfer coefficient is obtained for the bed particle diameter of $0.444 \mathrm{~mm}$ with the fluidization velocity close to the minimum fluidization velocity. Meanwhile, the highest average heat transfer coefficient is recorded for $U_{g} / U_{m f}=10.18$. It is evident that higher superficial gas velocity leads to faster heat flow between the fluidized bed and the superheater tube surface, as the average heat transfer coefficient showed an upward trend. At a sufficiently high fluidization velocity (i.e. $6.66<U_{g} / U_{m f}<10.18$ ) coalescence takes place resulting in large gas bubbles which tend to cause a higher frequency of packet replacement, and good heat transfer is obtained. Besides, heat transfer characteristics in an external heat exchanger with horizontal tube bundles can be explained by means of amended bed fluidization quality (i.e. decrease of gas bubble size and increase of bubble frequency) and dynamic gas bubble flow at the tube surface with the variation of system pressure. Thus, the variation of $h_{\text {avg }}$ is essentially affected by gas bubble action (i.e. growing bubble motion) at the heat transfer surface together with the downward sliding motion of bed particles or packets.

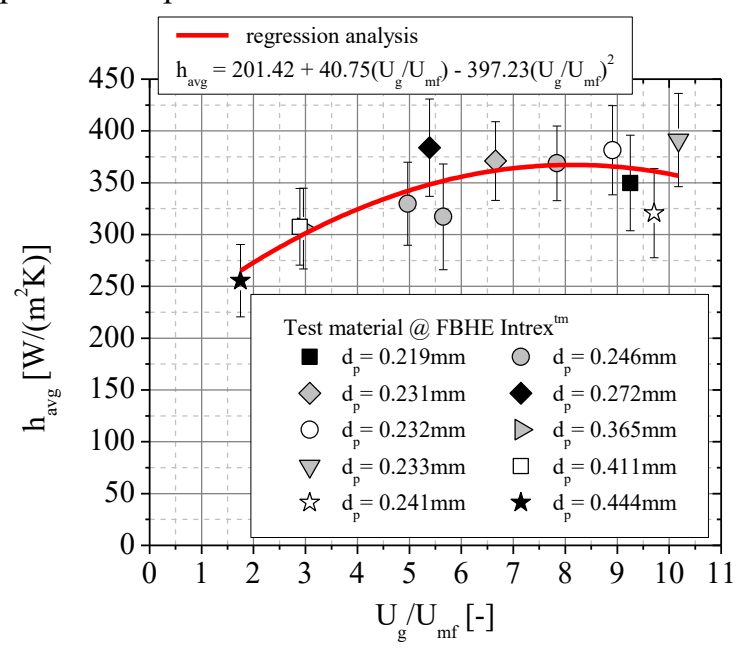

Fig. 4. Estimated average heat transfer coefficient from bed to tube at different fluidization numbers.

A polynomial of order two was fitted to plot the average heat transfer coefficient versus the fluidization number. The red curve in Fig. 4 is almost smooth with a medium gradient for coarse particles (i.e. $d_{p}>0.365 \mathrm{~mm}$ ). Moreover, at the fluidization number covering a range of 6.66-8.91, the values of the average heat transfer coefficient slightly increase at a certain superficial velocity and then remain almost constant for $0.232 \mathrm{~mm}<d_{p}<0233 \mathrm{~mm}$. Nevertheless, the preliminary increase of the average bed-to-tube heat transfer coefficient with fluidization number is caused by reduction in packet particles (emulsion) and residence time (i.e. from $0.25 \mathrm{~s}$ to $0.17 \mathrm{~s}$ ), and further decrease is due to an increase in the bed porosity in vicinity of the tube wall at a higher fluidization velocity (i.e. $0.22<U_{g}<0.25 \mathrm{~m} / \mathrm{s}$ ), as is depicted by determining the correlation function (red curve). In the current heat transfer study, the optimum fluidizing velocity equalled $0.25 \mathrm{~m} / \mathrm{s}$ for an enhancement of heat transfer rate in FBHE. As is seen from figure 4, the agreement between the correlation function and the predicted heat transfer data points is good $\left(R^{2}=0.6\right.$, moderate positive correlation $)$ for all particles (i.e. coarse, middle and fine particles).

\subsection{The correlation between average heat transfer data and bed temperature for the horizontal superheater tube}

Figure 5 illustrates the variation of the calculated average heat transfer coefficient at different bed temperatures. The error bars displayed designate the variation of the average bed-to-tube heat transfer coefficient in multiple performance tests in a large-scale $1296 \mathrm{t} / \mathrm{h}$ CFB boiler. As the bed temperature varied between $929 \mathrm{~K}$ and $950 \mathrm{~K}$, a high variation of average heat transfer coefficient for coarse particles is observed. For middle and fine bed particles, the normalized bed temperature had little effect on heat transfer rate, which follows from the red curve trend in Figure 5. The computed heat transfer coefficients slightly increased for bed temperatures in a range of 1071$1083 \mathrm{~K}$, except fine $\&$ middle particle sizes: $0.219 \mathrm{~mm}$, $0.231 \mathrm{~mm}$ and $0.246 \mathrm{~mm}$, respectively.

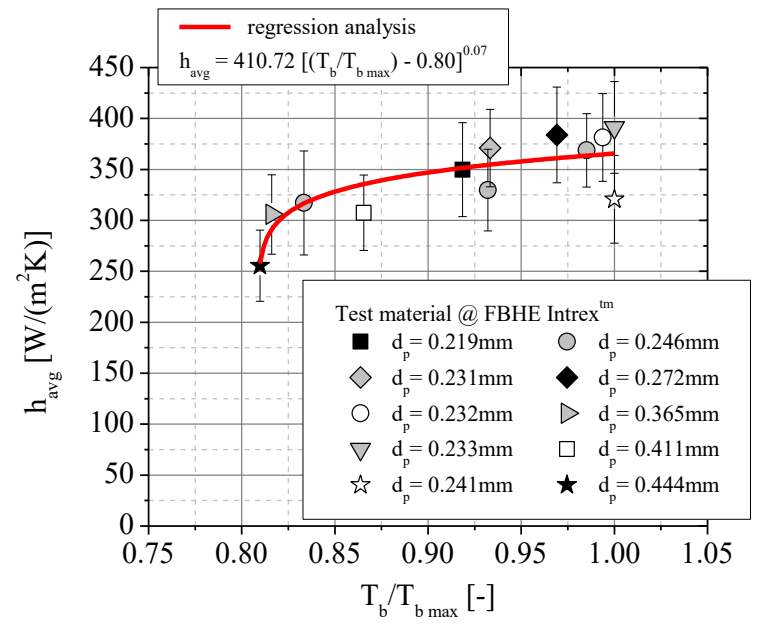

Fig. 5. Estimated average heat transfer coefficient from bed to tube at different normalized bed temperatures.

The higher values of heat transfer coefficient are probably a consequence of enough high suspension density and also a dominant role of the particle-convection component in the heat transfer mechanism. At the same time, the gas convection heat transfer coefficient decreased as a result of the decrease in gas phase density in a high temperature bed.

The average heat transfer coefficient to horizontal tube immersed in a fluidized bed is correlated to the normalized bed temperature $T_{b} / T_{b \max }$, by this potential function:

$$
h_{a v g}=a\left[\left(T_{b} / T_{b \max }\right)-b\right]^{c} .
$$

Here, $T_{b}$ denotes bed temperature, $T_{b} \max$ represents the maximum value of bed temperature during tests, $c$ means exponent, $a$ and $b$ are regression coefficients. The values of the parameters in the above mentioned correlation $a, b$, 
$c$ were found by regression analysis and they are displayed in Fig. 5. Graph 5 presents a moderate positive correlation for heat transfer data values at varying normalized bed temperatures $\left(R^{2}=0.64\right)$. A similar trend of heat transfer coefficient increasing with bed temperature variation was observed by Stenberg el al [5], Botterill et al. [22] and reported by Prins [23].

\section{Conclusions}

The averaged heat transfer coefficients were computed from the raw data coming from 12 performance tests at an industrial CFB unit. The packed renewal model offers a convenient way to investigate the impact of key variables on heat transfer in bubbling fluidized beds with Geldart B powder. It was found that the model was satisfactory for all mean bed particle sizes. The average heat transfer coefficient heavily depended upon mean particle size, particle concentration in vicinity of tube surface, bed temperature and al so fluidization quality.

A $n$ effort is made here to develop a correlation for large scale fluidized bed heat exchangers which can be used to predict $h_{\text {avg }}$ with success. Moreover, a few empirical correlations with satisfactory good fit computational results obtained from a mechanistic model were developed. The obtained correlation functions are applicable to a wide range of Sauter mean particle diameters, similar fluidization conditions and also staggered tube bundles. These empirical correlations can be useful for engineering design or heat transfer characteristics in fluidized bed heat exchangers with horizontal tube bundles.

\section{Acknowledgments}

This work was financially supported by scientific research no BS-PB -400/301/19.

\section{References}

1. Wey M.Y., Lin Ch.L., You S.D., Fluidized behaviour and heat transfer in a bubbling fluidized bed incinerator, J. Environ. Eng. Manage., Vol.17(3), pp. 169-175, (2007).

2. Kim S.W., Kim S.D., Heat transfer characteristics in a pressurized fluidized bed of fine particles with immersed horizontal tube bundle, Int. J. Heat Mass Tran., Vol. 64, pp. 269-277, (2013).

3. Merzsch M., Lechner S., Krautz H.J., Heat transfer from single horizontal tubes in fluidized beds: Influence of tube diameter, moisture and diameter definition by Geldart C fines content, Power Technol., Vol.235, pp. 1038-1046, (2013).

4. Di Natale F., Bareschino P., Nigro R., Heat transfer and void fraction profiles around a horizontal cylinder immersed in a bubbling fluidised bed, Int. J. Heat Mass Tran., Vol.53, pp. 3525-3532, (2010).

5. Stenberg V., Sköldberg V., Öhryby L., Rydén M., Evaluation of bed-to-tube surface heat transfer coefficient for a horizontal tube in bubbling fluidized bed at high temperature, Powder Technol., Vol. 352, pp. 488-500, (2019).
6. Blaszczuk A., Pogorzelec M., Shimizu T., Heat transfer characteristics in a large-scale bubbling fluidized bed with immersed horizontal tube bundles, Energy, Vol. 162, pp. 10-19, (2018).

7. Mickley H.S., Fairbanks D.F., Mechanism of heat transfer of fluidized beds, AIChE J., Vol.1, pp. 374384, (1955).

8. Yang W.Ch. (ed.), Fluidization, solids, handling, and processing. Industrial Applications, Noyes Publications, Westwood, New Jersey, USA, (1998).

9. Yang W.Ch. (ed.), Handbook of fluidization and fluid-particle systems, Marcel Dekker Inc., New York, (2003).

10. Baskakov A.P., Berg B.V., Vitt O.K., Fillippovsky N.F., Kirakosyan V.A., Goldobin J.M., M askaev V.K., Heat transfer to objects immersed in fluidized bed, Powder Technol., Vol.8, pp. 273-282, (1973).

11. Glickeman L.R., Decker N.A., Design relationship for predicting heat transfer to tube bundles in fluidized bed combustion. In: Proceedings of the sixth annual international conference on fluidized bed combustors, A tlanta, GA, Vol. III, pp. 11521158, (1980).

12. K unii D., L evenspielen O., Fluidization engineering. Butterworth-Heinemann, London,(1991).

13. Ozkaynak T.F., Chen J.C., Emulsion phase residence time and its use in heat transfer models in fluidized beds, AIChE Journal, Vol.26, pp. 544-550, (1980).

14. Blaszczuk A., Nowak W., Heat transfer behavior inside a furnace chamber of large-scale supercritical CFB boiler, Int. J. Heat Mass Tran., Vol.87, pp. 464480, (2015).

15. Blaszczuk A., Zylka A., Leszczynski J., Simulation of mass balance behaviour in a large-scale circulating fluidized bed reactor, Particuology, Vol. 25, pp. 5158, (2016).

16. US Patent No US 6962676B1, Method and apparatus in a fluidized bed heat exchanger, (2005).

17. Wang L., Wu P., Ni X., Surface-particle-emulsion model of heat transfer between a fluidized bed and a immersed surface, Powder Technol., Vol.149, pp. 127-138, (2005).

18. Parmar M.S., Hayhurst A.N., The heat transfer coefficient for a freely moving sphere in a bubbling fluidised bed, Chem. Eng. Sci., Vol.57, pp. 34853494, (2002).

19. Pidwerbecki D., Welty J.R., Heat transfer to a horizontal tube in the splash zone of a bubbling fluidized bed, an experimental study of particle size effects, Exp. Therm. Fluid Sci., Vol.10(3), pp. 307317, (1995).

20. M asoumifarad N, M ostoufi N, Hamidi A A, SotudehGharebagh R., Investigation of heat transfer between a horizontal tube and gas-solid fluidized bed, Int. $J$ Heat Fluid Flow, Vol.29, pp. 1504-1511, (2008).

21. Lu P, Cao Y., Pan W.P., Ma Ch., Heat transfer characteristics in a horizontal swirling fluidized bed, Exp. Therm. Fluid Sci., Vol.35, pp. 1127-1134, (2011).

22. Botterill J.S.M., Teoman Y., Yüregir K.R., Temperature effects on the heat transfer behaviour of 
gas fluidised beds, AIChE Symposium Series, 77, pp.330-340, (1981).

23. Prins W., Fluidised bed combustion of a single carbon particle, PhD Thesis, Twente University, Netherlands, (1987). 